Superalloys 2012: $12^{\text {th }}$ International Symposium on Superalloys

\title{
Evolution of Grain Boundary Precipitates in a Directionally Solidified Ni-base Superalloy during High Temperature Creep
}

\author{
Dong Wang ${ }^{1}$, Chang Liu ${ }^{1}$, Jian Zhang ${ }^{1,2}$, Langhong Lou ${ }^{1}$ \\ ${ }^{1}$ Superalloys Division, Institute of Metal Research, Chinese Academy of Sciences, 72 Wenhua Road, Shenyang 110016, China \\ ${ }^{2}$ Shenyang National Laboratory for Materials Science, Institute of Metal Research, Chinese Academy of Sciences, 72 Wenhua Road, \\ Shenyang 110016, China
}

Keywords: Superalloy, Creep, Boride, Grain boundary, Phase transformation

\begin{abstract}
The evolution of grain boundary phases during high temperature creep has been systematically investigated in a directionally solidified Ni-base superalloy. At the primary creep stage, precipitation of nanosize $\mathrm{M}_{5} \mathrm{~B}_{3}$ boride from $\gamma$ matrix and phase transformation from $\mathrm{M}_{23}(\mathrm{C}, \mathrm{B})_{6}$ borocarbide to $\mathrm{M}_{5} \mathrm{~B}_{3}$ boride occur at grain boundaries. At the steady-state creep stage, precipitation of blocky $\mathrm{M}_{23}(\mathrm{C}, \mathrm{B})_{6}$ borocarbide and coarsening of $\mathrm{M}_{23}(\mathrm{C}, \mathrm{B})_{6}$ with the dissolution of $\mathrm{M}_{5} \mathrm{~B}_{3}$ boride occur at grain boundaries. At the tertiary creep stage, precipitation of $\mathrm{M}_{5} \mathrm{~B}_{3}$ boride from $\gamma$ matrix or phase transformation from $\mathrm{M}_{23}(\mathrm{C}, \mathrm{B})_{6}$ borocarbide to $\mathrm{M}_{5} \mathrm{~B}_{3}$ boride occur again at grain boundaries. The precipitation of $\mathrm{M}_{5} \mathrm{~B}_{3}$ is due to diffusion of $\mathrm{B}$ atoms promoted by applied tensile stress during high temperature creep, and the phase transformation between $M_{23}(C, B)_{6}$ and $M_{5} B_{3}$ is thought to correlate strongly with the strain rate of different creep stages.
\end{abstract}

\section{Introduction}

Directional solidification (DS) and single crystal (SC) Ni-base superalloys are widely used as blade materials in advanced aircraft and stationary gas turbines because of their excellent mechanical properties at high temperatures [1]. In operating gas turbine engines, an important part of the damage experienced by rotating turbine blades is due to creep deformation [2]. For this reason, a great number of studies have been conducted investigating the creep behavior of superalloys. The two prominent features of DS and SC Ni-base superalloys during high temperature creep deformation are the rapid development of interfacial dislocation networks and directional coarsening or "rafting" of the $\gamma^{\prime}$ precipitates [3, 4].

Compared to SC Ni-base superalloys, DS Ni-base superalloys have a particular creep deformation characteristic due to presence of the longitudinal grain boundaries (GBs). The formation of premature cavity and microcrack always concentrates on the GBs during creep, especially at high temperatures where GB sliding becomes a significant deformation mechanism [5-7]. In order to suppress or delay this mode of intergranular failure, trace amount of $\mathrm{C}$ and $\mathrm{B}$ are added $[8,9]$.

The beneficial effects of $\mathrm{C}$ are derived primarily from the intergranular carbides, and the effects of carbides upon high temperature properties are dependent upon the type of carbide present and its morphology. No all-inclusive statement can be made concerning the most desirable type and morphology of carbides $[10,11]$. In general optimum high temperature properties are obtained when $\mathrm{M}_{23} \mathrm{C}_{6}$ is present as discrete particles distributed uniformly along the GBs [12-14]. However, much less effort has been devoted to the detailed study of precipitation and evolution mechanism of intergranular $\mathrm{M}_{23} \mathrm{C}_{6}$ during high temperature creep.

It is well accepted that B segregates to the GBs, and a variety of possible strengthening mechanisms include: (1) increasing GBs cohesive strength, lowering GBs diffusivity and GBs surface energy $[15,16],(2)$ hindering the diffusion of tramp elements to GBs [17, 18], (3) promoting the cross slip of dislocations and the migration of dislocations across the GBs [19, 20], and (4) decreasing the agglomeration of $\mathrm{M}_{23} \mathrm{C}_{6}$ concurrently with depletion of $\gamma^{\prime}$ from the adjacent matrix and preventing formation of topologically closed-packed phases [21, 22]. However, it should be emphasized that the precise role played by the B element is uncertain. $\mathrm{B}$ additions over the solubility limit are shown to result in the intergranular precipitation of the $\mathrm{M}_{3} \mathrm{~B}_{2}$ compound and caused no further improvement or deterioration in mechanical properties [23, 24]. Moreover, it is not clear whether or not presence of any other borides strengthening the GBs.

It should be mentioned that little is known concerning the synergetic effects of $C$ and $B$, except that $B$ can substitute for $C$ in $\mathrm{M}_{23} \mathrm{C}_{6}$ structure [25]. Considering (1) the precipitation and evolution mechanism of intergranular carbide occurred at high temperature creep are not clear, (2) the direct experimental evidence supporting above actual strengthening mechanisms of B is seldom found, and (3) the creep strength of DS Ni-base superalloys correlates very strongly with the microstructure of GBs, it is of utmost important to gather information about the intergranular regions during creep. Therefore, the primary objective of the present work was to employ transmission electron microscopy (TEM) techniques to study the evolution of GB microstructure during high temperature creep, especially focusing on phase precipitation and transformation, trying to obtain the direct experimental evidence revealing the actual strengthening mechanisms of $\mathrm{C}$ and $\mathrm{B}$.

\section{Experimental Procedures}

The nominal composition in weight percent (wt. \%) of the alloy used in this work was $8 \mathrm{Cr}, 1 \mathrm{Mo}, 9 \mathrm{Co}, 6 \mathrm{~W}, 2 \mathrm{Ta}, 1 \mathrm{Nb}, 5 \mathrm{Al}, 2 \mathrm{Ti}$, $0.1 \mathrm{C}, 0.01 \mathrm{~B}$, balance $\mathrm{Ni}$. The experimental alloy was initially vacuum induction melted and cast into polycrystalline ingots. The ingot was remelted and directionally solidified by the high gradient liquid metal cooling (LMC) process. The ceramic mold used in LMC was designed to cast a cluster of four cylindrical bars with $18 \mathrm{~mm}$ in diameter and $220 \mathrm{~mm}$ in length.

The solution treatment was performed at $1265^{\circ} \mathrm{C}$ for 4 hours after heating at $1160{ }^{\circ} \mathrm{C}$ for 2 hours as a pre-homogenization to avoid any chance of incipient melting. A two-step aging treatment was performed, first at $1110{ }^{\circ} \mathrm{C}$ for 4 hours and second at $850{ }^{\circ} \mathrm{C}$ for 24 hours, both followed by air-cooling. 
The heat-treated bars with [001] orientation were machined into creep specimens with gauge length of $50 \mathrm{~mm}$ and a gauge diameter of $8 \mathrm{~mm}$. Constant load tensile creep tests were performed in ambient atmosphere at $975{ }^{\circ} \mathrm{C}$ under a stress of 255 MPa. Most of the creep tests were interrupted for microstructural examinations, whereas some tests were run to failure.

Heat treated sample was cut, ground and polished. The TEM slices were mechanically thinned down to a thickness of approximately $50 \mu \mathrm{m}$. Discs of $3 \mathrm{~mm}$ in diameter were punched out of the thin sheets and electro-polished with $90 \mathrm{pct}$ alcohol and 10 pct perchloric acid electrolyte at $-25{ }^{\circ} \mathrm{C}$ and $20 \mathrm{~V}$, using a double-jet electropolisher.

Electron probe microanalyzer (EPMA) was used to characterize the distribution of B after heat treatment. The TEM was used to identify and analyse the phases using selected area diffraction (SAD) and energy dispersive spectrometer (EDS).

\section{Results}

\section{GB Phase before Creep}

Figure 1(a) is a typical EPMA mapping of $B$, from which the enrichment of B along the GB was observed after heat treatment. TEM micrograph of heat treated specimen (Figure 1(b)) shows that the GB was extensively decorated with blocky precipitates. According to the SAD of precipitate and EPMA mapping of B analysis, it can be confirmed that the blocky precipitate was $\mathrm{M}_{23}(\mathrm{C}, \mathrm{B})_{6}$ borocarbide. $\mathrm{M}_{23}(\mathrm{C}, \mathrm{B})_{6}$ borocarbide had an FCC structure with a cube-cube orientation relationship with the $\gamma$ matrix:

$$
[001]_{M_{23}(C, B)_{6}} / /[001]_{\gamma},(100)_{M_{23}(C, B)_{6}} / /(100)_{\gamma}
$$

No other borides were observed.

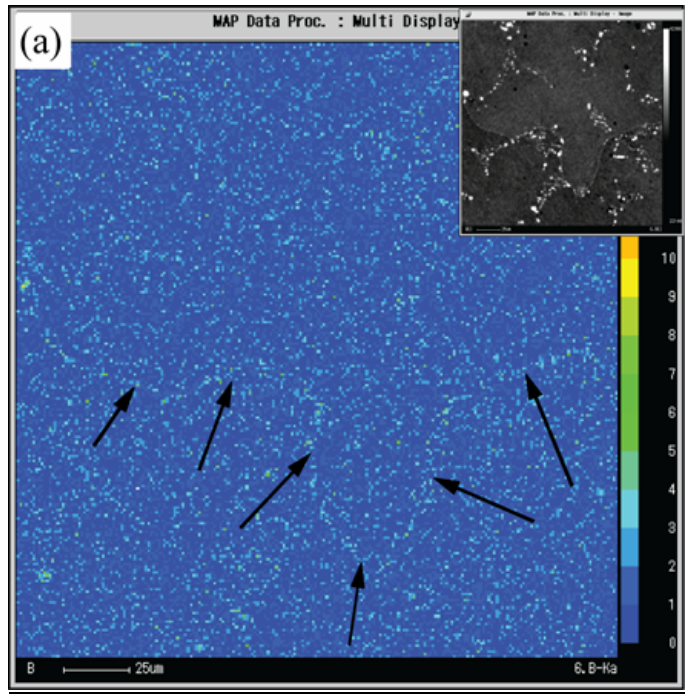

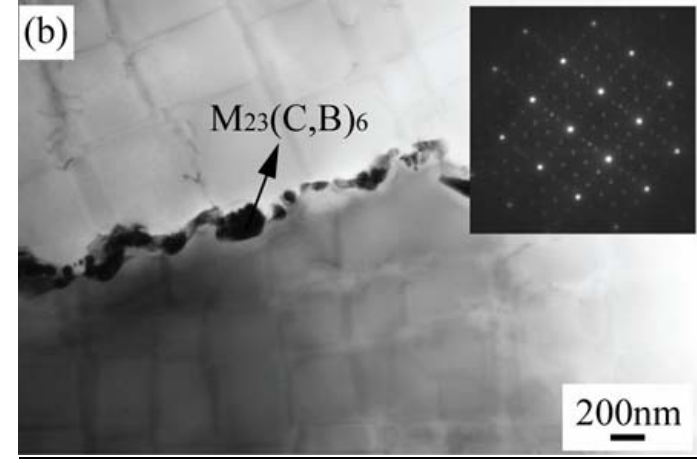

Figure 1. (a) EPMA mapping of B and (b) TEM micrograph of GB after heat treatment are shown.

\section{Creep Testing}

A typical creep curve for the present alloy at $975{ }^{\circ} \mathrm{C} / 255 \mathrm{MPa}$ is shown in Figure 2. Microstructure at four stages during the creep was examined: after $2 \mathrm{~h}, 14 \mathrm{~h}, 40 \mathrm{~h}$ and $100 \mathrm{~h}$ of creep deformation (points A, B, C and D in Figure 2), respectively.

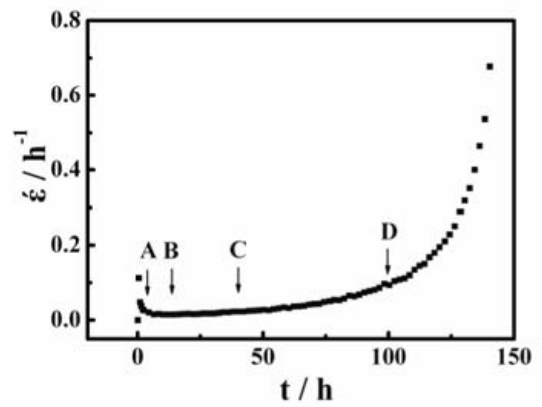

Figure 2. Creep curve of the experimental alloy at $975{ }^{\circ} \mathrm{C} / 255$ MPa.

\section{GB Phase at Primary Creep Stage}

Although the creep time was very short at point A (2 h), a low magnification TEM micrograph (Figure 3(a)) shows that some dislocations were activated and have propagated in the $\gamma$ matrix, and a continuous film-like precipitate was observed along GB. Closer examination at higher magnification (Figure 3(b)) indicated that the film-like precipitate was composed of many closely contacted fine nanosize particles. The SAD analysis demonstrated that these precipitates possessed the same crystal structure and they were $\mathrm{Cr}_{5} \mathrm{~B}_{3}$-type $\mathrm{M}_{5} \mathrm{~B}_{3}$ boride with a body centered tetragonal structure. Based on the analyses of SAD, the orientation relationship between the boride and $\gamma$ matrix can be determined as follows:

$[001]_{M_{5} B_{3}} / /[001]_{\gamma},(\overline{3} 10)_{M_{5} B_{3}} / /(0 \overline{2} 0)_{\gamma}$

Based on Figure 3(b), it can be also found that besides precipitation of $\mathrm{M}_{5} \mathrm{~B}_{3}$ boride from $\gamma$ matrix, phase transformation from $M_{23}(C, B)_{6}$ to $M_{5} B_{3}$ also occurred at the primary creep stage.

Microchemical analysis of the particles by TEM-EDS showed that 
the composition of $\mathrm{M}_{5} \mathrm{~B}_{3}$ boride contained a very high level of $\mathrm{W}$, Mo and $\mathrm{Cr}$ (Figure 3(c)).
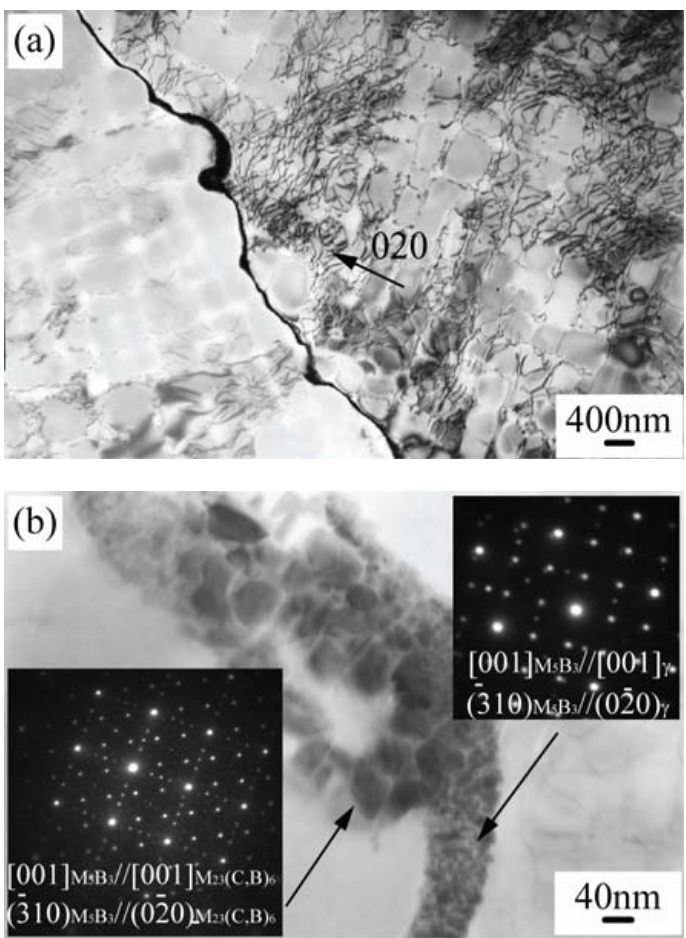

(c)

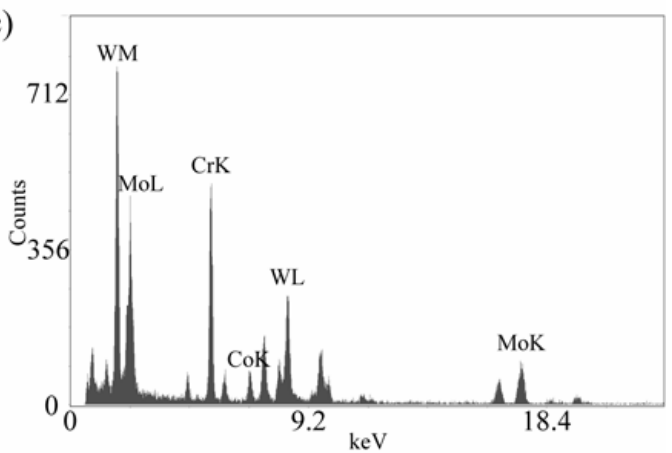

Figure 3. TEM micrographs of sample after $2 \mathrm{~h}$ of creep deformation at $975{ }^{\circ} \mathrm{C} / 255 \mathrm{MPa}$ are shown. (a) Lowmagnification GB micrograph. (b) High-magnification GB micrograph and the corresponding diffraction diagram of precipitate. (c) Typical EDS obtained from the precipitate in Figure 3 (b).

\section{GB Phase at Initial Stage of Steady-State Creep Stage}

Figure 4(a) is a representative TEM micrograph of sample after 14 h of creep deformation at $975{ }^{\circ} \mathrm{C} / 255 \mathrm{MPa}$. Although the dislocations grew continuously in the $\gamma$ matrix passages with the progress of creep, the $\mathrm{SAD}$ analysis demonstrated that these precipitates were still $\mathrm{M}_{5} \mathrm{~B}_{3}$ boride. No significant change for $\mathrm{M}_{5} \mathrm{~B}_{3}$ boride in morphology was noticed by comparison of Figure 3 and Figure 4.

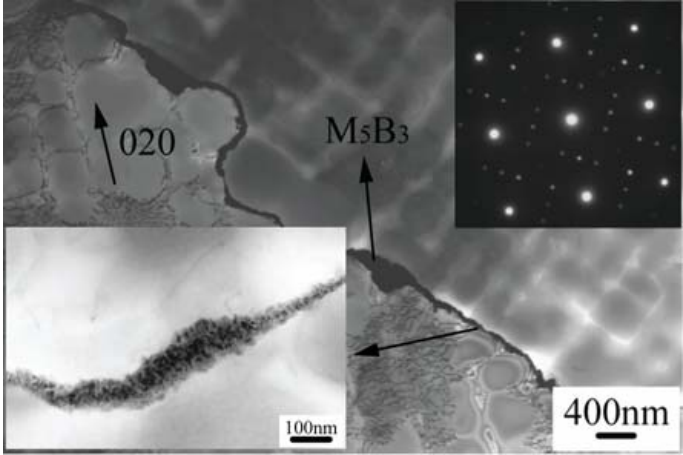

Figure 4. TEM micrographs of sample after $14 \mathrm{~h}$ of creep deformation at $975{ }^{\circ} \mathrm{C} / 255 \mathrm{MPa}$ is shown.

\section{GB Phase at Middle Stage of Steady-State Creep Stage}

As the creep time reached $40 \mathrm{~h}$ (point $\mathrm{C}$ in Figure 2), the interfacial dislocation networks were formed. Meanwhile, the precipitate morphology at GB changed from continuous film-like to discrete block-like (Figure 5(a)). The analysis of SAD from the particles demonstrated that these precipitates were mainly $\mathrm{M}_{23}(\mathrm{C}, \mathrm{B})_{6}$ borocarbide. However, detailed SAD analysis (Figure 5 (b)) indicated that small fraction of $M_{5} B_{3}$ boride may also exist at the GB, although $\mathrm{M}_{5} \mathrm{~B}_{3}$ can not be found from Figure 5(a). This indicated that $M_{5} B_{3}$ boride was dissolving gradually during the steady-state creep stage.

According to the orientation relationship between $\mathrm{M}_{5} \mathrm{~B}_{3}$ and $\gamma$ matrix (Figure 3(b)), it can be inferred that the [020] orientation of $\gamma$ matrix from which $\mathrm{M}_{5} \mathrm{~B}_{3}$ precipitated was parallel (or vertical) to direction II or III, as shown in Figure 5(b). And the [020] orientation of $\gamma$ matrix from which $\mathrm{M}_{23}(\mathrm{C}, \mathrm{B})_{6}$ precipitated was parallel (or vertical) to direction IV, as shown in Figure 5(b). Therefore, it was interesting to note that $\mathrm{M}_{23}(\mathrm{C}, \mathrm{B})_{6}$ particles were precipitated from the adjoining grain of the grain from which $\mathrm{M}_{5} \mathrm{~B}_{3}$ precipitated and coarsening with the dissolution of the $\mathrm{M}_{5} \mathrm{~B}_{3}$ during high temperature creep. By qualitative analysis the typical TEM-EDS results shown in Figure 3(c) and Figure 5(c), it can be found that the composition of $\mathrm{M}_{23}(\mathrm{C}, \mathrm{B})_{6}$ and $\mathrm{M}_{5} \mathrm{~B}_{3}$ was similar, both containing a very high level of $\mathrm{W}$, Mo and $\mathrm{Cr}$. The major difference was the content of $\mathrm{Cr}$ in the $\mathrm{M}_{23}(\mathrm{C}, \mathrm{B})_{6}$ was higher compared to that in $\mathrm{M}_{5} \mathrm{~B}_{3}$.

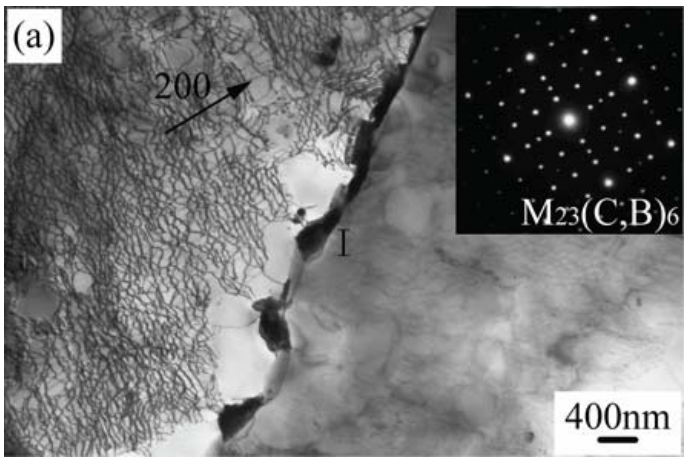




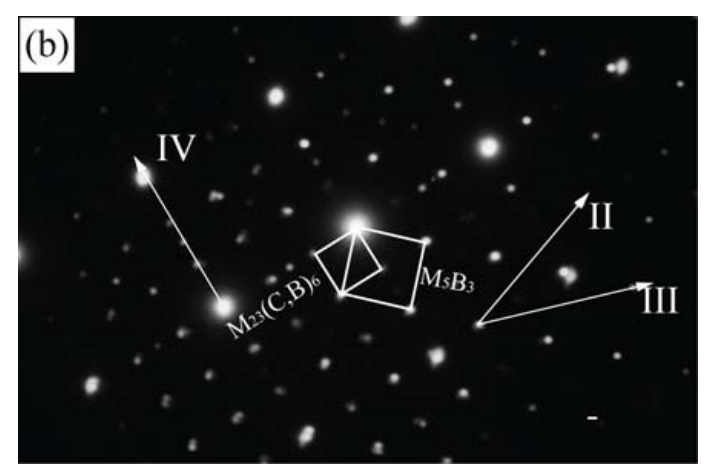

(c)

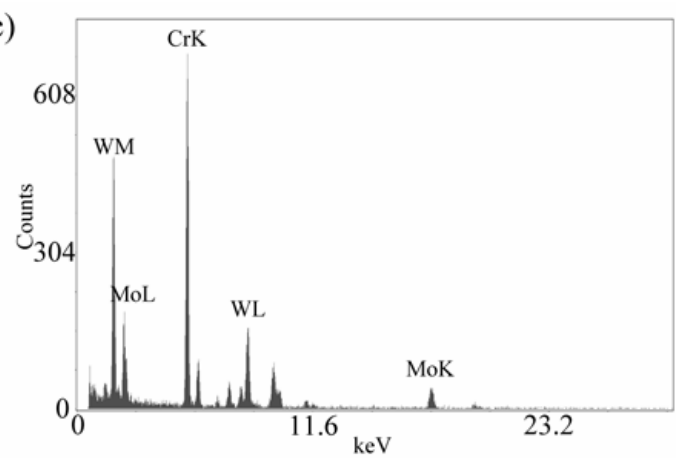

Figure 5. TEM micrographs of sample after $40 \mathrm{~h}$ of creep deformation at $975{ }^{\circ} \mathrm{C} / 255 \mathrm{MPa}$ are shown. (a) GB micrograph and the corresponding diffraction diagram of precipitate. (b) Corresponding diffraction diagram of I position in Figure 5(a). (c) Typical EDS obtained from the precipitate in Figure 5(a).

\section{GB Phase at Initial Stage of Tertiary Creep Stage}

As the creep time reached $100 \mathrm{~h}$ (point D in Figure 2), the interfacial dislocation networks at the $\gamma / \gamma^{\prime}$ interface were locally damaged, some dislocations cut through the $\gamma^{\prime}$ particles, leaving dislocation couples in the $\gamma^{\prime}$. A continuous film-like $\mathrm{M}_{5} \mathrm{~B}_{3}$ boride was again observed along GB, besides block-like $\mathrm{M}_{23}(\mathrm{C}, \mathrm{B})_{6}$ borocarbide (Figure 6). From Figure 6, it can be found that the size of $\mathrm{M}_{5} \mathrm{~B}_{3}$ boride was also in nanometer scale. However, it was unknown that if $\mathrm{M}_{5} \mathrm{~B}_{3}$ boride at the tertiary creep stage was precipitated from $\gamma$ matrix or transformed from $\mathrm{M}_{23}(\mathrm{C}, \mathrm{B})_{6}$.

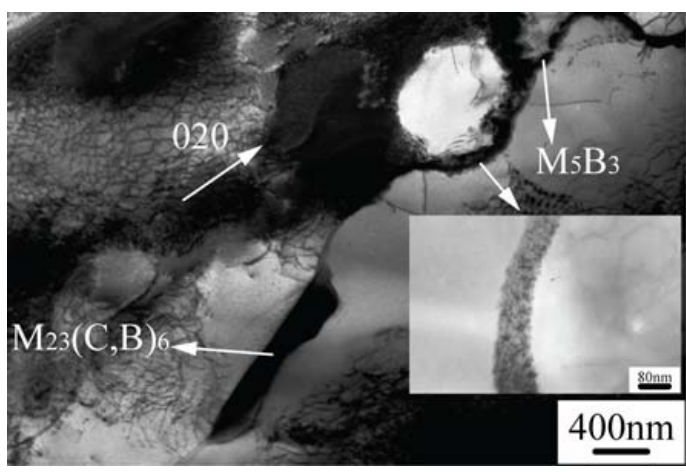

Figure 6. TEM micrographs of sample after $100 \mathrm{~h}$ of creep deformation at $975{ }^{\circ} \mathrm{C} / 255 \mathrm{MPa}$ is shown.

\section{Discussion}

The most striking characteristics of GBs during $975{ }^{\circ} \mathrm{C} / 255 \mathrm{MPa}$ creep deformation were GB phase evolutions. The precipitation of $\mathrm{M}_{5} \mathrm{~B}_{3}$ from $\gamma$ matrix and phase transformation from $\mathrm{M}_{23}(\mathrm{C}, \mathrm{B})_{6}$ to $\mathrm{M}_{5} \mathrm{~B}_{3}$ occurred at the primary creep stage; precipitation of $\mathrm{M}_{23}(\mathrm{C}, \mathrm{B})_{6}$ from $\gamma$ matrix and coarsening of $\mathrm{M}_{23}(\mathrm{C}, \mathrm{B})_{6}$ with the dissolution of $\mathrm{M}_{5} \mathrm{~B}_{3}$ occurred at the steady-state creep stage; precipitation of $\mathrm{M}_{5} \mathrm{~B}_{3}$ from $\gamma$ matrix or phase transformation from $M_{23}(C, B)_{6}$ to $M_{5} B_{3}$ occurred at the tertiary creep stage.

\section{Precipitation Mechanism of $\mathrm{M}_{5} \underline{\mathrm{B}}_{3}$}

In general, for DS Ni-base superalloys containing high content of $\mathrm{Cr}, \mathrm{M}_{23} \mathrm{C}_{6}$ or $\mathrm{M}_{23}(\mathrm{C}, \mathrm{B})_{6}$ usually formed at GBs during heat treatment or high temperature creep. However, precipitation of $\mathrm{M}_{5} \mathrm{~B}_{3}$ borides was seldom observed at GBs [26], especially during high temperature creep.

In view of crystal structures of $\mathrm{M}_{5} \mathrm{~B}_{3}$ and $\gamma$ matrix, the lattice correspondence between $\mathrm{M}_{5} \mathrm{~B}_{3}$ and $\gamma$ matrix can be inferred based on Figure 3(b), as shown in Figure 7(a). The corresponding relationship between (001) atomic plane of $\mathrm{M}_{5} \mathrm{~B}_{3}$ and (002) atomic plane of $\gamma$ matrix is depicted in Figure 7 (b). According to Figure 7 , the lattice parameters of $\mathrm{M}_{5} \mathrm{~B}_{3}$ can be calculated (the lattice parameter of $\gamma$ matrix $\mathrm{a}_{\gamma}$ approximately equals $3.6 \mathrm{~nm}$ ):

$$
\begin{aligned}
& a_{M_{5} B_{3}}=\sqrt{\left(\frac{3}{2}\right)^{2}+\left(\frac{1}{2}\right)^{2}} a_{\gamma}=1.58 a_{\gamma} \approx 0.569 \mathrm{~nm} \\
& c_{M_{5} B_{3}}=3 a_{\gamma}=1.08 \mathrm{~nm}
\end{aligned}
$$

The calculated lattice parameters of $\mathrm{M}_{5} \mathrm{~B}_{3}$ coincided well with the data reported in handbook $\left(\mathrm{a}_{0}=0.5699 \mathrm{~nm}, \mathrm{c}_{0}=1.088 \mathrm{~nm}\right)$ [27]. Therefore, Figure 7 probably exhibited correctly the lattice relationship between $\mathrm{M}_{5} \mathrm{~B}_{3}$ and $\gamma$ matrix.

(a)

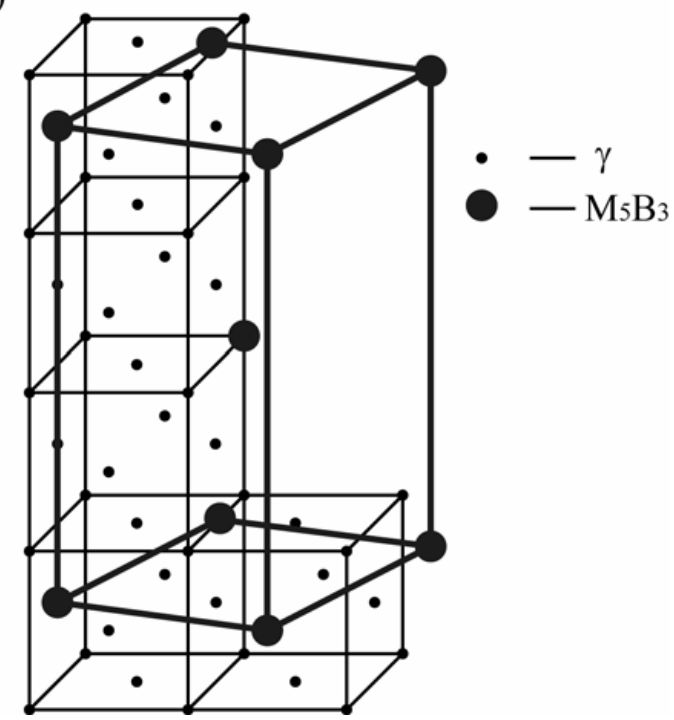


(b)

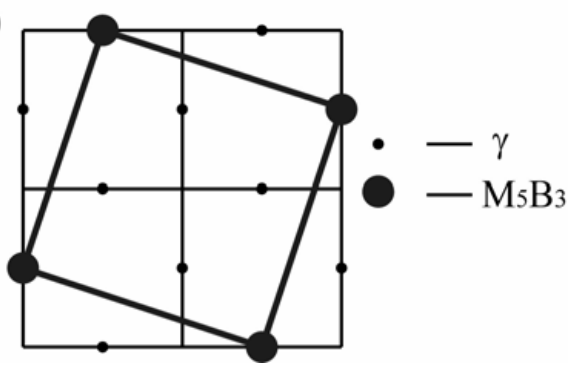

Figure 7. (a) Depiction of lattice correspondence between $\mathrm{M}_{5} \mathrm{~B}_{3}$ and $\gamma$ matrix. (b) Depiction of relationship between (001) atomic plane of $\mathrm{M}_{5} \mathrm{~B}_{3}$ and (002) atomic plane of $\gamma$ matrix.

According to Figure 7, eight corner atoms of $\mathrm{M}_{5} \mathrm{~B}_{3}$ were all located at $\gamma$ matrix face centered sites, and the center atom of $\mathrm{M}_{5} \mathrm{~B}_{3}$ boride was located at $\gamma$ matrix cornered site. It is well accepted that B atoms stay at octahedral interstitial sites of $\gamma$ lattice as schematically illustrated in Figure 8. Therefore, the formation of $\mathrm{M}_{5} \mathrm{~B}_{3}$ required $\mathrm{B}$ atoms diffusing from the octahedral interstitial sites to the face centered sites. In general, this diffusion was difficult to occur, thus $\mathrm{M}_{5} \mathrm{~B}_{3}$ was seldom found after heat treatment. However, it has been well established that DS Ni-base superalloys deformed by operation of $a / 2<101>$ dislocations on $\{111\}$ planes in $\gamma$ matrix during high temperature creep when the loading direction was parallel to $<001>$. This activated the movement of matrix atoms, from site 2 to site 1 in Figure 8 . During this process, B atoms may diffuse easily under an applied uniaxial tensile stress, from site 3 to site 2 . It seemed that the nucleation kinetics of $\mathrm{M}_{5} \mathrm{~B}_{3}$ was rather rapid during the primary creep stage, since extensive nanosize particles were observed in Figure 3. High strain rate promoted this process.

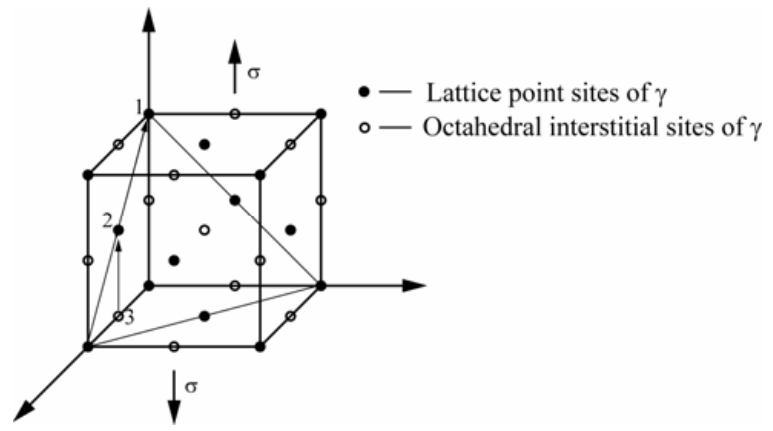

Figure 8. Illustration of B atoms diffusion under uniaxial tensile stress is shown.

Phase Transformation Mechanism from $\mathrm{M}_{\underline{2}}(\mathrm{C}, \mathrm{B})_{\underline{6}} \underline{\text { to }} \mathrm{M}_{\underline{5}} \underline{\mathrm{B}_{3}}$

The strain rate at the initial stage of primary creep and tertiary creep was very high. Therefore, many dislocations were activated and propagated in $\gamma$ matrix at the GBs quickly. However, due to presence of precipitate particles, these dislocations piled up at the $\gamma /$ precipitate interface, which resulted in high strain energy at GBs. In general, the larger the size of the precipitate, the higher strain energy was expected. Thus, in order to decrease strain energy, blocky $\mathrm{M}_{23}(\mathrm{C}, \mathrm{B})_{6}$ borocarbide might transform into nanosize $\mathrm{M}_{5} \mathrm{~B}_{3}$ boride, whose composition was similar to $\mathrm{M}_{23}(\mathrm{C}, \mathrm{B})_{6}$, but size was apparently smaller than that of $\mathrm{M}_{23}(\mathrm{C}, \mathrm{B})_{6}$. This phase transformation can avoid stress concentration at the $\gamma / \mathrm{M}_{23}(\mathrm{C}, \mathrm{B})_{6}$ interface, retard the onset of creep cavitation and rupture. Generally, this phase transformation can not occur in B-free alloys. Therefore, it can be inferred that avoiding stress concentration by phase transformation was perhaps one of the strengthening mechanisms of B.

Precipitation and Coarsening Mechanisms of $\mathrm{M}_{23}(\mathrm{C}, \mathrm{B})_{6}$

The strain rate at steady-state creep stage was very low, creep process was governed by thermal diffusion. The formation of $\mathrm{M}_{5} \mathrm{~B}_{3}$ boride caused $\mathrm{W}$, Mo, and $\mathrm{Cr}$ depletion at GBs during primary creep stage. Accompanied by high temperature creep, stress may induce the flow of $\mathrm{W}, \mathrm{Mo}, \mathrm{Cr}$ atoms from intragranular regions towards GBs. Considering the large diffusion rate of $\mathrm{Cr}$ and its small atom radii, it may be expected that diffusion of $\mathrm{Cr}$ was more pronounced. Consequently, $\mathrm{M}_{23}(\mathrm{C}, \mathrm{B})_{6}$ borocarbide would form in view of strong segregations of $\mathrm{C}$ and $\mathrm{B}$ atoms at the GBs.

Based on above results, it can be found that $\mathrm{M}_{23}(\mathrm{C}, \mathrm{B})_{6}$ borocarbide not only formed, but also coarsened with the dissolution of $M_{5} B_{3}$ boride driven by the decrease in interface energy at steady-state creep stage. The reason why nanosize $M_{5} B_{3}$ boride did not coarsen was that: The lattice misfit between $\mathrm{M}_{5} \mathrm{~B}_{3}$ and matrix was non-coherent, however, according to Reference [28], it can be inferred that the atomic configuration of $\{111\}$ planes in the $\mathrm{M}_{23}(\mathrm{C}, \mathrm{B})_{6}$ and matrix lattices was similar and the lattice misfit between $\mathrm{M}_{23}(\mathrm{C}, \mathrm{B})_{6}$ and matrix was very small and be partially coherent. Hence, the elastic energy that coarsening of $\mathrm{M}_{5} \mathrm{~B}_{3}$ per unit volume overcame was higher than that of $\mathrm{M}_{23}(\mathrm{C}, \mathrm{B})_{6}$.

\section{Conclusion}

The following conclusions can be drawn from analysis of the results obtained in this work:

(1) During high temperature creep, applied tensile stress promotes diffusion of B atoms from octahedral interstitial sites of $\gamma$ lattice to face centered sites of $\gamma$ lattice, resulted in precipitation of many nanosize $\mathrm{M}_{5} \mathrm{~B}_{3}$ boride particles at GBs. The orientation relationship between $\mathrm{M}_{5} \mathrm{~B}_{3}$ boride and $\gamma$ matrix is:

$$
[001]_{M_{5} B_{3}} / /[001]_{\gamma},(\overline{3} 10)_{M_{5} B_{3}} / /(0 \overline{2} 0)_{\gamma}
$$

(2) The strain rate is found to have a significant influence on the evolution of GB phase during high temperature creep. High strain rate induces phase transformation from $\mathrm{M}_{23}(\mathrm{C}, \mathrm{B})_{6}$ to $\mathrm{M}_{5} \mathrm{~B}_{3}$, and low strain rate induces precipitation of $\mathrm{M}_{23}(\mathrm{C}, \mathrm{B})_{6}$ from $\gamma$ matrix and coarsening of $\mathrm{M}_{23}(C, B)_{6}$ with the dissolution of $\mathrm{M}_{5} \mathrm{~B}_{3}$.

\section{Acknowledgement}

This work was financially supported by the National Basic Research Program (973 Program) of China under grant No. 2010CB631201 and the National Natural Science Foundation of China under grant No. 51101160, 51171193. The authors are grateful for those supports.

\section{References}

1. C.T. Sims, N.S. Stoloff, and W.C. Hagel, Superalloys II 
(New York, NY: John Wiley \& Sons, 1987), 191-214.

2. R.C. Reed, The Superalloys Fundamentals and Applications (New York, NY: Cambridge University Press, 2006), 170-187.

3. T.P. Gabb et al., "The Role of Interfacial Dislocation Networks in High Temperature Creep of Superalloys," Materials Science and Engineering A, 118 (1989), 59-69.

4. N. Matan et al., "On the Kinetics of Rafting in CMSX-4 Superalloy Single Crystals,” Acta Materialia, 47 (7) (1999), 2031-2045.

5. A.J. Perry, "Review Cavitation in Creep," Journal of Materials Science, 9 (1974), 1016-1039.

6. W. Chen, and M.C. Chaturvedi, "Dependence of Creep Fracture of Inconel 718 on Grain Boundary Precipitates," Acta Materialia, 45 (7) (1997), 2735-2746.

7. X.J. Wu, and A.K. Koul, "Grain Boundary Sliding in the Presence of Grain Boundary Precipitates during Transient Creep,” Metallurgical and Materials Transactions A, 26 (1995), 905-914.

8. L. Xiao, D.L. Chen, and M.C. Chaturvedi, "Effect of Boron on Fatigue Crack Growth Behavior in Superalloy IN 718 at RT and $650{ }^{\circ} \mathrm{C}$,” Materials Science and Engineering A, 428 (2006), 1-11.

9. Q.Z. Chen, C.N. Jones, and D.M. Knowles, "The Grain Boundary Microstructures of the Base and Modified RR 2072 Bicrystal Superalloys and Their Effects on the Creep Properties," Materials Science and Engineering A, 385 (2004), 402-418.

10. A.K. Koul, and R. Castillo, "Assessment of Service Induced Microstructural Damage and Its Rejuvenation in Turbine Blades,” Metallurgical Transactions A, 19 (1988), 2049-2066.

11. A.K. Koul, and W. Wallace, "A Note on the Microstructural Dependence of Creep Strength in Inconel 700,” Metallurgical Transactions A, 13 (1982), 673-675.

12. G.P. Sabol, and R. Stickler, "Microstructure of NickelBased Superalloys,” Physical Status Solidi, 35 (1969), 1152.

13. P.E. Li et al., "Influence of Intergranular Carbide Density and Grain Size on Creep of Fe-15Cr-25Ni Alloys," Metallurgical Transactions A, 23 (1992), 1379-1381.

14. R.M. Kruger, and G.S. Was, "The Influence of Boron on the Grain Boundary Chemistry and Microstructure of $\mathrm{Ni}$ 16Cr-9Fe-0.03C," Metallurgical Transactions A, 19 (1988), 2555-2566.

15. C.S. Lee et al., "The Influence of Boron-doping on the Effectiveness of Grain Boundary Hardening in $\mathrm{Ni}_{3} \mathrm{Al}$," Acta Materialia, 47 (6) (1999), 1823-1830.
16. C.T. Liu, C.L. White, and J.A. Horton, "Effect of Boron on Grain-boundaries in $\mathrm{Ni}_{3} \mathrm{Al}$," Acta Metallurgica, 33 (2) (1985), 213-229.

17. U. Franzoni, F. Marchetti, and S. Sturlese, "Effects of Grain Boundary Segregation and Precipitation on the Creep Behaviour of a 20Cr, Al-Ti, Ni-base Superalloy,” Scripta Metallurgica, 19 (1985), 511-516.

18. S. Floreen, and J.M. Davidson, "The Effects of B and Zr on the Creep and Fatigue Crack Growth Behavior of a NiBase Superalloy,” Metallurgical Transactions A, 14 (1983), 895-901.

19. E.M. Schulson et al., "Grain Boundary Accommodation of Slip in $\mathrm{Ni}_{3} \mathrm{Al}$ Containing Boron,” Acta Metallurgica, 34 (7) (1986), 1395-1399.

20. Y.L. Chiu, and A.H.W. Ngan, "Effects of Boron Doping on the Grain-Growth Kinetics and Mechanical Properties of $\gamma / \gamma^{\prime}$ Nickel-Aluminum Alloys,” Metallurgical and Materials Transactions A, 31 (2000), 3179-3186.

21. R.F. Decker, and J.W. Freeman, "The Mechanism of Beneficial Effects of Boron and Zirconium on Creep Properties of a Complex Heat-resistant Alloy," Transactions of the Metallurgical Society of AIME, 218 (1960), 277-285.

22. R.V. Nandedkar, and W. Kesternich, "Effect of Boron on High-temperature Creep Behavior of Austenitic Stainless Steel DIN 1.4970," Metallurgical Transactions A, 21 (1990), 3033-3038.

23. T.J. Garosshen, T.D. Tillman, and G.P. McCarthy, "Efects of $\mathrm{B}, \mathrm{C}$, and $\mathrm{Zr}$ on the Structure and Properties of a $\mathrm{P} / \mathrm{M}$ Nickel Base Superalloy,” Metallurgical Transactions A, 18 (1987), 69-77.

24. L. Xiao, D.L. Chen, and M.C. Chaturvedi, "Effect of Boron and Carbon on Thermomechanical Fatigue of IN 718 Superalloy,” Materials Science and Engineering A, 437 (2006), 157-171.

25. M.A. Burke et al., "The Effect of Boron and Carbon on the Microstructural Chemistries of Two Wrought Nickel Base Superalloys,” Scripta Metallurgica, 18 (1984), 91-94.

26. H.R. Zhang, O.A. Ojo, and M.C. Chaturvedi, "Nanosize Boride Particles in Heat-treated Nickel Base Superalloys," Scripta Materialia, 58 (2008), 167-170.

27. J.S Lu., B. Wang, and Y.C. Yao, Manual for the Determination of the Common Phases in Steels and Alloys by X-ray (Beijing: Beijing Institute of Steel and Iron Research Press, 1990), 37-40.

28. F.R. Beckitt, B.R. Clark, "The Shape and Mechanism of Formation of $\mathrm{M}_{23} \mathrm{C}_{6}$ Carbide in Austenite," Acta Metallurgica, 15 (1967), 113-129. 